\title{
Methodology for environmental assessments of oil and hazardous substance spills*
}

\author{
W. P. Davis ${ }^{1}$, G. I. Scottt ${ }^{1,2}$, C. D. Getter ${ }^{2}$, \\ M. O. Hayes ${ }^{3}$ \& E. R. Gundlach ${ }^{2}$ \\ 1 Environmental Protection Agency, Bears Bluff Laboratory, Post Office Box 368, Johns \\ Island, South Carolina 29455, USA, \\ ${ }^{2}$ Research Planning Institute, Inc, 806 Pavillion Avenue, Columbia, South Carolina \\ 29205, USA, \\ and \\ 3 Coastal Research Division, Department of Geology, University of South Carolina; \\ Columbia, South Carolina, 29208, USA
}

\begin{abstract}
Scientific assessment of the complex environmental consequences of large spills of oil or other hazardous substances has stimulated development of improved strategies for rapid and valid collection and processing of ecological data. The combination of coastal processes and geological measurements developed by Hayes \& Gundlach (1978), together with selected field biological and chemical observations/measurements, provide an ecosystem impact assessment approach which is termed "integrated zonal method of ecological impact assessment." Ecological assessment of oil and hazardous material spills has been divided into three distinct phases: (1) firstorder response studies - conducted at the time of the initial spill event, which gather data to document acute impacts and assist decision-makers in prioritization of cleanup efforts and protection of ecologically sensitive habitats, (2) second-order response studies - conducted two months to one year post-spill, which document any delayed mortality and attempt to identify potential sublethal impacts in sensitive species, and (3) third-order response studies-conducted one to three years post-spill, to document chronic impacts (both lethal and sublethal) to specific indicator species. Data collected during first-order response studies are gathered in a quantitative manner so that the initial assessment may become a baseline for later, more detailed, post-spill scientific efforts. First- and second-order response studies of the "Peck Slip" oil spill in Puerto Rico illustrate the usefulness of this method. The need for contingency planning before a spill has been discussed along with the use of the Vulnerability Index, a method in which coastal environments are classified on a scale of 1-10, based upon their potential susceptibility to oiling. A study of the lower Cook Inlet section of the Alaskan coast illustrates the practical application of this method.
\end{abstract}

\section{INTRODUCTION}

Within the past two years (1978 to present), we have witnessed a series of petroleum spillages which surpasses all records for volume of oil or area of impact. New publications (e. g., Oil Spill Intelligence Report) report on a weekly basis the locality, extent of public reaction, and environmental impact of petroleum spills. Butler (1978) reviewed 30 of the largest spills through 1978 and recommended international reporting and analyses of the total problem.

\footnotetext{
* Contribution 402, Gulf Breeze Environmental Research Laboratory
} 
Yet, of the impacts of man's activities upon ocean or coastal environments, there is still no general agreement that the catastrophe of a large spill represents a permanent scar in the ecosystem. This uncertainty can probably be best ascribed to man's inability to grasp the holistic nature of marine ecosystems or to establish time-series data collections which would best define the processes, changes, and results of such events.

The initial responses to very large oil spills tend to fall into categories of emergency response. As the event continues, questions arise regarding how to mitigate and measure spill impact; thus arises the need for broad-base scientific observations and studies.

Environmental assessment must incorporate data from the physical, geological, chemical, and biological components of the ecosystem. The joining together of geologists, coastal processes specialists, ecologists, and environmental chemists has stimulated the evolution of what is termed an "integrated zonal method of ecological impact assessment."

\section{INTEGRATED ZONAL METHOD FOR POST-SPILL FIRST-ORDER ASSESSMENT}

The integrated zonal method of study is a combination of rapid survey of geomorphological features in coastal environments, together with documentation of the biological habitats, and sampling of representative species present. This approach emphasizes ecological and biological observations and provides a rapid assessment method for estimating initial ecological damage during the initial spill impact of a coastline. Such preliminary investigations, conducted at the time of the initial impact event, are termed first-order assessment studies.

The zonal method of study, outlined by Hayes \& Gundlach (1978), provides the framework for rapid, oil-impact assessment during the preliminary stages of a spill. This method utilizes a team of two geologists and one to two biologists who measure:

(1) Detailed geological mapping along a transect at a permanently marked shoreline which provides information on both vertical elevation, sediment grain size, and habitat stability (erosional or depositional).

(2) Detailed quantification of both the amount and extent of surface and subsurface visible oil within impacted habitats.

(3) Detailed biological qualitative and quantitative data collection at both control and impacted areas with censusing techniques, including live counts of flora, epifauna, and infauna (macrofauna $\geq 1.00 \mathrm{~mm}$ ), which provide the framework for comparison baseline data (either pre-spill versus post-spill or control versus impact population dynamics comparisons). Samples are collected using both $\mathrm{m}^{2}$ counts and core/sieving techniques. Measurements of the percentage, height, and thickness of visible oil coverage on producers and consumers are also made. Behavioral tests (such as the righting response of snails or the timing of escape behavior in crabs) are conducted in the field. Additional dead body counts are conducted in areas where oil (or other spilled substances) has proven acutely toxic.

(4) Detailed chemical sampling of water, sediments, and major producers and consumers (including both ecologically and commercially important species) which emphasize trophic structure relationships (food-chain approach) so as to investigate any potential biological concentration or magnification which may occur. Later chemical analysis of collected samples provides additional information on the weathering, abso- 
lute quantities, and chemical species of oil (or other spilled substances) which may be related to observed biological impacts. This is very important since many areas adjacent to visibly oiled areas may be impacted by the lighter (more toxic), water-soluble oil fractions. Additionally, chemical analysis assists in separating causes of mortality, such as physical oil coverage (smothering effect) from toxicity directly attributable to the lighter, more toxic oil fractions.

(5) Photographic documentation of observations, including both color and infrared photography.

(6) Detailed sampling of physical processes such as longshore drift direction and velocity; wind direction and velocity; wave height, approach angle, and period; tidal current direction, velocity, and duration.

The essence of this method is based on the geomorphology of the environment which will determine the degree of susceptibility to oil deposition and the persistence of oil within different coastal environments. Susceptibility to oil deposition is based on elevation and the degree of exposure to waves, tides, and currents. Persistence of oil is based upon the degree of oil penetration which is a function of sediment grain size, the chemical nature of the spilled oil, and the degree of exposure to waves and tides.

As originally proposed, this zonal method of study only emphasized quantifying the extent of oiling present in impacted areas, with limited quantitative considerations of initial biological impacts. The incorporation of detailed biological and chemical sampling strategies with the zonal method results in an integrated zonal approach which provides simultaneous geological, biological, chemical, and physical assessment of oilspill impact by one research team.

The use of this integrated approach in first-order assessment studies allows a preliminary estimate of the extent of ecological damage resulting from the initial spill and also provides the information needed to prioritize efforts to protect ecologically sensitive habitats (such as nursery grounds for larval fishes or nesting grounds for rare or endangered species). Additionally, data are provided which identify areas where cleanup responses are feasible and the types of cleanup procedures to be used. Furthermore, first-order assessments provide a basis for prediction of potential biological effects and assist in designing more intensive and longer-term studies.

\section{"PECK SLIP" OIL SPILL: \\ AN EXAMPLE OF A POST-SPILL FIRST-ORDER RESPONSE}

Shortly after $3 \mathrm{pm}$ on 19 December 1978, the 105-m barge "Peck Slip" sustained structural damage in heavy seas off the northeast coast of Puerto Rico. It proceeded to release approximately 1510-1565 tons of medium-grade Bunker C petroleum distillate into the marine environment. Field studies undertaken by our group (beginning on 22 December 1978 and concluding on 6 January 1979) revealed a total of $26 \mathrm{~km}$ of sand, gravel, and cobble beaches and red mangrove forests were impacted (Robinson, 1979). Oil impact on beaches was minimal, with some impact of beach morning glories (Ipomea pes-caprae) growing at the base of the foredune. It was anticipated that the most severe impact would develop in the ecologically sensitive mangrove forests at Puerto Medio Mundo and Pasaje Medio Mundo, where approximately 4.8 metric tons of oil reached some seven acres of red mangrove (Rhizophora mangle) forest (see Fig. 1). 


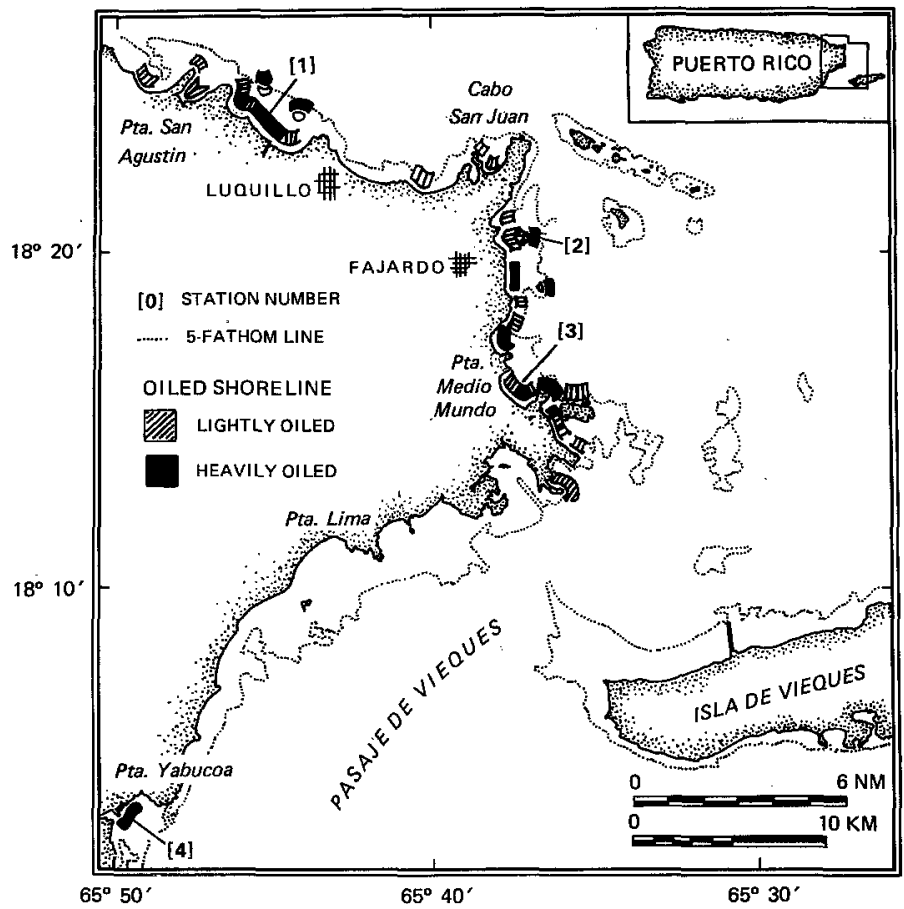

Fig. 1. Map of northeastern Puerto Rico, depicting the areas impacted by the "Peck Slip" oil spill

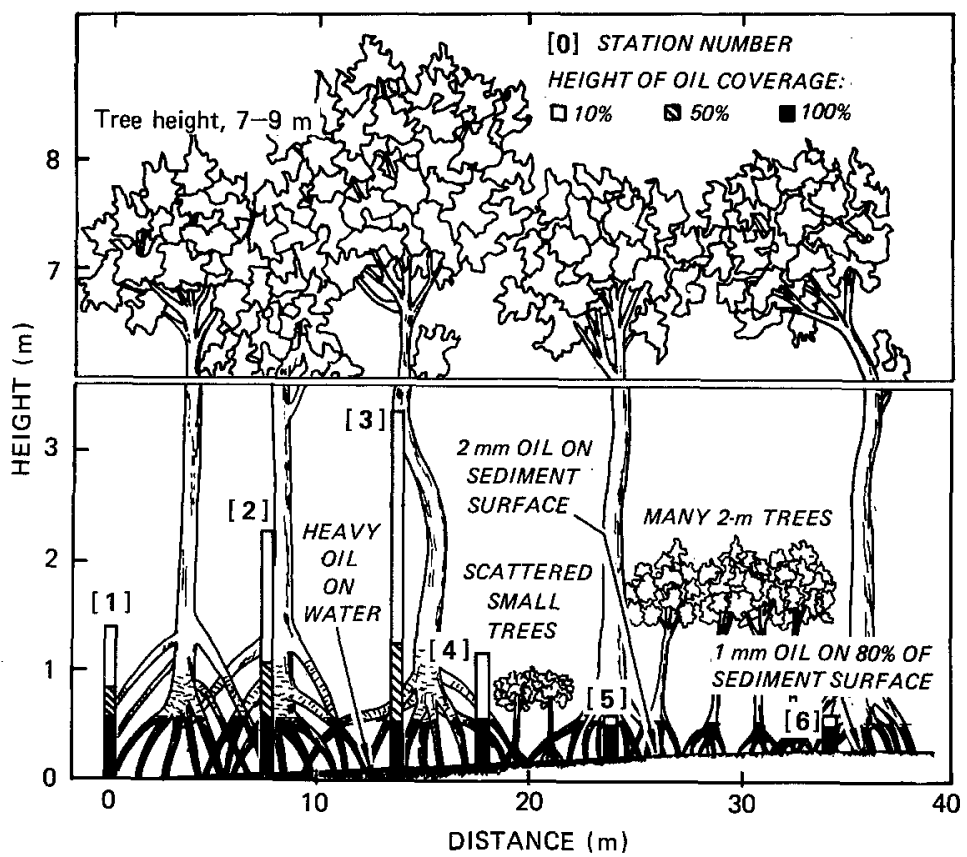

Fig. 2. Transect M-1 at the red mangrove forest at Puerto Medio Mundo, depicting the oiling of the prop roots of the adult trees. The height and thickness of oil coverage is useful in estimating the volume of oil in these ecologically sensitive habitats 
Detailed surveys in the mangrove forests at Puerto Medio Mundo and Pasaje Medio Mundo revealed that impact was confined to: (a) heavy oil coating on red mangrove prop roots and the associated epiphytic prop root community, including several species of algae, sponges, tunicates, hydroids, anemones, oysters, and barnacles (see Fig. 2); (b) heavy oil coverage of associated epifaunal species, including three species of crabs (mangrove crab Aratus pisonii, tree crab Goniopsis cruentata, and Sally Lightfoot crab Grapsus grapsus) and two species of gastropods (angulate periwinkle snail Littorina angulifera and salt marsh snail Melampus coffeus).

The function of the root in the red mangrove is to act as a gas-exchange surface in providing oxygen to the submerged roots. A heavy coating of oil will interfere with the normalflux of $\mathrm{H}_{2} \mathrm{O}, \mathrm{CO}_{2}$, and $\mathrm{O}_{2}$ from photosynthetic and respiratory processes. Snedaker (U. of Miami, personal communication) states that the breakdown of $\mathrm{O}_{2}$ transport to the roots may result in the disruption of nutrient cycles in the rhizosphere. This may, in turn, result in the breakdown of the osmotic function of the cell wall, causing death. Chan (1977) additionally reports that tree mortalities occurred rapidly when $50 \%$ or more of the roots were covered by oil. Since oil coverage of prop roots exceeded $50 \%$ in many areas, it is reasonable to expect considerable tree mortality, especially in seedlings.

The most heavily impacted epifaunal organisms were the mangrove crabs Aratus pisonii. Their carapaces, chelipeds, and walking legs were totally (90-100\%) covered with oil, which resulted in the inability of these usually very active crabs to avoid capture. In some areas, heavily oiled crabs assumed a praying position characterized by chelipeds extended in front and walking legs extended in back. This position may be a premortem response as many dead crabs were found in this position, glued to the mangrove by sticky oil; however, this was only true of heavily oiled crabs.

Although both species of snails (Littorina angulifera and Melampus coffeus) were heavily oiled, both exhibited normal feeding behavior; no obvious impact was observed.

\section{MODIFICATION OF INTEGRATED ZONAL METHOD FOR SECOND- AND THIRD-ORDER POST-SPILL STUDIES}

Second- and third-order response efforts initiate quantitative approaches to chronic biological effects, based upon preliminary results during first-order response studies.

Second-order studies are primarily designed to measure any delayed lethal or sublethal biological impacts for several months to one year after initial spill impact. These efforts include field bioassays, caging experiments, continued quantitative sampling for biological baseline data, and productivity measurements.

Third-order responses address more chronic life-history impacts, such as disruption of normal cellular histopathology, genetic impairment or disruption, and alteration or modification of normal physiological pathways. These studies are designed to measure impact for one to three years after the initial spill event.

Whereas first-order response studies attempt to quantify direct or lethal impacts on an acute basis, second- and third-order response studies are designed to measure indirect or sublethal impacts on a chronic basis. Such second- and third-order studies were begun after the "Amoco Cadiz" spill. Although more expensive and time-consuming than the immediate first-order response studies, second- and third-order studies are geared for determining the duration of environmental impact, and provide the only 
evidence for making a judgment as to whether or not an area has recovered biologically from oil impact.

A revisit to the "Peck Slip" spill site, some three months after the initial impact, provided an excellent example as to the value of second- and third-order response studies.

Table 1. Chronic effects measured in Puerto Rican mangrove forest at Puerto Medio Mundo approximately three months after the initial "Peck Slip" oil spill impact

\begin{tabular}{|c|c|}
\hline Criteria & Change (percent damage) \\
\hline \multicolumn{2}{|c|}{$\begin{array}{l}\text { Producers } \\
\text { (1) Red mangrove trees (Rhizophora mangle) } \\
\text { Adults }\end{array}$} \\
\hline Mortality (percent) & Increase $(25 \%)$ \\
\hline \multicolumn{2}{|l|}{ Lenticels } \\
\hline Prop roots $\left(\mathrm{cm}^{-2}\right)$ & Increase in variability \\
\hline Trunk $\left(\mathrm{cm}^{-2}\right)$ & Increase in variability \\
\hline Defoliation (percent) & Increase $(39 \%)$ \\
\hline \multicolumn{2}{|l|}{ Seedlings } \\
\hline Mortality (percent) & Increase $(25 \%)$ \\
\hline Leaf deformities index & Increase \\
\hline \multicolumn{2}{|l|}{ (2) Epiphytes (Bostrychia sp.) } \\
\hline Biomass $\left(\mathrm{mg} \mathrm{cm}^{-2}\right)$ & Decrease $(36 \%)$ \\
\hline Water content (percent) & Decrease (18\%) \\
\hline Organic content (percent) & Decrease $(17 \%)$ \\
\hline Carbon-nitrogen ratio & Increase (26\%) \\
\hline \multicolumn{2}{|c|}{$\begin{array}{l}\text { Cons u mers } \\
\text { (1) Tree snails (Littorina angulifera) }\end{array}$} \\
\hline Distribution uniformity & Decrease \\
\hline Growth rate $(\mathrm{mm} / 90 \mathrm{~d})$ & Decrease $(21 \%)$ \\
\hline \multicolumn{2}{|l|}{ (2) Tree crabs (Aratus pisonii) } \\
\hline Population denstiy $\left(\mathrm{m}^{-2}\right)$ & Decrease $(86 \%)$ \\
\hline
\end{tabular}

Table 1 lists the chronic changes measured in oil-impacted red mangrove forest communities at Puerto Medio Mundo and Pasaje Medio Mundo in northeastern Puerto Rico. Adult red mangrove tree mortality significantly $(\mathrm{p} \leq 0.05)$ increased in impacted areas by $24.7 \%$. This reduces standing-stock biomass of the dominant producer by approximately $25 \%$. Red mangrove tree defoliation also significantly $(p \leq 0.05)$ increased in impacted areas by $38.6 \%$. This impact will ultimately cause a loss of approximately $39 \%$ of the detritus material normally formed in these areas. Seedling mortality significantly ( $\mathrm{p} \leq 0.05$ ) increased by $24.7 \%$ in oil-impacted areas.

Epiphytic communities showed significantly degraded fitness in biomass $(35.1 \%$ reduced), desiccation (17\% increased), organic content $(17.4 \%$ decreased), and carbon/ nitrogen ratios $(25.9 \%$ increased $)$.

Populations of consumers were significantly impacted. Littorina angulifera showed alteration of horizontal and vertical distribution, and a $21.4 \%$ decrease in growth rate. Aratus pisonii suffered an $86.1 \%$ reduction in population. 
Results of this second-order response study indicated significantly more impact than the original first-order response study provided. Although preliminary first-order response studies did indicate a high probability of impact in heavily oiled red mangrove communities, a second-order response study was required to quantify the extent of ecological damage.

The estimate of ecological damage generated from first-, second-, and third-order studies may be turned over to lawyers and economists, who will translate this information into meaningful monetary damage estimates. These estimates are based upon information collected on the degree of impact of primary commercially important species (e. g., oysters, crabs, and shrimp), secondary commercially important species (species utilized for food by primary commercially important species), and ecologically important species (of primary and secondary importance) combined with ecological information (e. g., trophic relationships) currently available in scientific literature. While this is, scientifically, a more meaningful method for quantifying economic damage, dead body counts of impacted organisms have formed the only legally accepted basis for computing estimates of monetary damage during court proceedings.

\section{THE VULNERABILITY INDEX IN PRE-SPILL PLANNING}

Past oil spills, such as the "Peck Slip" and "Amoco Cadiz", have shown the need for pre-spill contingency planning, including biological and chemical baseline information. These data must be collected prior to actual spillage events, due to usual short periods of time between the spillage event and shoreline impact. The "Amoco Cadiz" spill, in particular, illustrates this point.

Another reason pre-spill data are important is that in many major spills, such large areas of shoreline are impacted (e.g., "Amoco Cadiz", $393 \mathrm{~km}$ of shoreline were impacted; Hess, 1978) that it is difficult to collect similar control baseline data, due to the dissimilar nature of the environment with increasing distance from the actual spill event.

In an attempt to classify coastlines in terms of sensitivity to oil, Gundlach \& Hayes (1978) proposed the "Vulnerability Index" in which the coastal environments were classified on a scale of 1 to 10, based upon their potential vulnerability to oil-spill damage (Table 2). The larger numbers indicate high vulnerability. As originally proposed, this index emphasized oil-residence time with consideration of potential biological impact.

This pre-spill study system utilizes the integrated zonal method of study previously described. Results are listed in a detailed report which includes detailed vulnerability maps (Michel et al., 1978). Areas with similar vulnerability (and, hence, similar geomorphic biotypes) are listed in accordance with their respective numerical location on the 1-10 scale.

Table 3 and Figure 3 illustrate the theoretical application of the Vulnerability Index to a hypothetical coastline (Gundlach \& Hayes, 1978), while Figure 4 illustrates the practical application of this method to the lower Cook Inlet section of the Alaskan coast (Michel et al., 1978).

The geomorphology of coastal environments will often influence and determine the types of ecological communities found there. For example: on a wave-cut platform, a very dense and highly diverse rocky shore community abounds; whereas on a sandy 
beach, a low diversity, less dense, specially adapted, burrowing community resides. Thus, the geomorphology of an area delineates the natural biological communities found there.

The recent integration of geological vulnerability (based on deposition, penetration, and persistence of spilled oil) and biological vulnerability (based on the species-specific sensitivity to spilled oil, length of exposure, rate of biological recovery, and toxic properties of spilled oil) results in a vulnerability index which properly assesses geological persistence as well as biological susceptibility. This method additionally establishes a pre-spill chemical and biological baseline of samples, which are only analyzed when an area is oil-impacted. Thus, this method conserves both time and resources since samples from unimpacted areas are not analyzed.

Table 2. Summary of proposed environmental classification in order of increasing vulnerability to oil-spill damage (after Gundlach \& Hayes, 1978)

\begin{tabular}{|c|c|c|}
\hline $\begin{array}{l}\text { Vulnerability } \\
\text { index }\end{array}$ & $\begin{array}{l}\text { Shoreline } \\
\text { type }\end{array}$ & Comments \\
\hline 1 & $\begin{array}{l}\text { Exposed rocky } \\
\text { headland }\end{array}$ & $\begin{array}{l}\text { Wave reflection keeps most of the oil offshore. No cleanup } \\
\text { necessary. }\end{array}$ \\
\hline 2 & $\begin{array}{l}\text { Eroding wave-cut } \\
\text { platform }\end{array}$ & $\begin{array}{l}\text { Wave-swept shoreline. Most of the oil is removed by natural } \\
\text { processes within a few weeks. }\end{array}$ \\
\hline 3 & $\begin{array}{l}\text { Fine-grained } \\
\text { sand beach }\end{array}$ & $\begin{array}{l}\text { Oil does not penetrate into the sediment, which facilitates } \\
\text { mechanical removal if necessary. Otherwise, oil may persist } \\
\text { for several months. }\end{array}$ \\
\hline 4 & $\begin{array}{l}\text { Coarse-grained } \\
\text { sand beach }\end{array}$ & $\begin{array}{l}\text { Oil may sink and/or be buried rapidly, making cleanup diffi- } \\
\text { cult. Under moderate-to-high energy conditions, oil will be } \\
\text { removed naturally within a few months from most of the } \\
\text { beach face. }\end{array}$ \\
\hline 5 & $\begin{array}{l}\text { Exposed, com- } \\
\text { pacted tidal flat }\end{array}$ & $\begin{array}{l}\text { Most of the oil will not adhere to, or penetrate into, the } \\
\text { compacted tidal flat. Cleanup is usually unnecessary. }\end{array}$ \\
\hline 6 & $\begin{array}{l}\text { Mixed sand and } \\
\text { gravel beach }\end{array}$ & $\begin{array}{l}\text { Oil may undergo rapid penetration and burial. Under mode- } \\
\text { rate-to-low energy conditions, oil may persist for years. }\end{array}$ \\
\hline 7 & Gravel beach & $\begin{array}{l}\text { Same as above. Cleanup should concentrate on the hightide } \\
\text { swash area. A solid asphalt pavement may form under condi- } \\
\text { tions of heavy oil accumulation. }\end{array}$ \\
\hline 8 & $\begin{array}{l}\text { Sheltered rocky } \\
\text { coast }\end{array}$ & $\begin{array}{l}\text { Areas of reduced wave action. Oil may persist for many years. } \\
\text { Cleanup is not recommended unless oil concentration is very } \\
\text { heavy. }\end{array}$ \\
\hline 9 & $\begin{array}{l}\text { Sheltered tidal } \\
\text { flat }\end{array}$ & $\begin{array}{l}\text { Areas of great biologic activity and low wave energy. Oil may } \\
\text { persist for years. Cleanup is not recommended unless oil } \\
\text { accumulation is very heavy. These areas should receive prio- } \\
\text { rity protection by using booms or oil-sorbent materials. }\end{array}$ \\
\hline 10 & $\begin{array}{l}\text { Salt marsh and } \\
\text { mangrove forest }\end{array}$ & $\begin{array}{l}\text { The most productive of aquatic environments. Oil may persist } \\
\text { for years. Cleaning of salt marshes by burning or cutting } \\
\text { should be undertaken only if heavily oiled. Mangroves } \\
\text { should not be altered. Protection of these environments by } \\
\text { booms or oil-sorbent materials should receive first priority. }\end{array}$ \\
\hline
\end{tabular}


Accompanying information on the location of wildlife preserves, bird sanctuaries, and areas utilized by rare or endangered species is also listed. In addition, anthropogenic areas (e.g., resort beaches and marinas) which have a high socioeconomic value are included as a separate category.

Another feature of the Vulnerability Index is that the sites for effective boom deployment are located. These boom locations are based on tidal current dynamics, channel configuration, and the designated vulnerability of the environment. This information assists the Coast Guard and spill cleanup officials during boom deployment under actual spill conditions. The Vulnerability Index also enables cleanup efforts in oilimpacted areas to be prioritized, starting with the most sensitive areas and ending with the least susceptible environments.

The practicality and usefulness of this method have been demonstrated in Vulnerability Index studies of the Alaskan coast, Puget Sound and the Straits of Juan de Fuca in the State of Washington, and most recently, the coastal environments of Texas (including Laguna Madre) during the "Ixtoc I" (Bay of Campeche) oil spill.

During the "Ixtoc I" oil spill, pre-spill Vulnerability Index mapping assisted the Coast Guard in formulating an effective method to minimize spill impact along the Texas coast. As a result of this effort, major intrusion of oil into the ecologically sensitive

Table 3. Shoreline morphology for a hypothetical coastline, using designated geomorphic types. This method of data presentation is useful for rapid assessment of the coastal geomorphology in selected study areas (after Gundlach \& Hayes, 1978)

\begin{tabular}{|lccc|}
\multicolumn{1}{c}{$\begin{array}{c}\text { Type } \\
\text { and } \\
\text { subtype }\end{array}$} & $\begin{array}{c}\text { Total } \\
\text { shoreline } \\
(\mathrm{km})\end{array}$ & $\begin{array}{c}\text { Percent } \\
\text { of total } \\
\text { shoreline }\end{array}$ & $\begin{array}{c}\text { Vulnerability } \\
\text { Index }\end{array}$ \\
\hline (A) Erosional shoreline (32\% of total) & & & \\
1. Cliffs $>30$ m high with wave-cut platform & 15 & 19 & $1-2$ \\
2. Cliffs <30 m high with wave-cut platform & 6 & 8 & $1-2,7-8^{*}$ \\
3. Eroding bank of inlet channel & 4 & 5 & $3-4$ \\
(B) Neutral shoreline (39\% of total) & & & \\
1. Mountainous, with steep high scarps & 5 & 7 & $7-8$ \\
2. Hilly lowland with low scarps & 4 & 5 & $1-2$ \\
3. Protected fine sand beaches & 9 & 12 & $3-4$ \\
4. Coarse sand beach & 6 & 8 & $3-4$ \\
5. Mixed sand and gravel beach & 2 & 3 & $5-6$ \\
6. Pocket gravel beach & 3 & 4 & $7-8$ \\
(C) Depositional shoreline (29\% of total) & & & \\
1. Arcuate delta & 1 & 1 & $3-4$ \\
2. Beach ridges & 2 & 3 & $3-4$ \\
3. Recurved spit & 1 & 1 & $3-4$ \\
4. Bay mouth bar & 1 & 1 & $3-4$ \\
5. Sand tidal flat & 3 & 4 & $5-6$ \\
6. Mud tidal flat & 5 & 7 & $9-10$ \\
7. Salt marsh & 9 & 12 & $9-10$ \\
* Half of shoreline (3 m, $4 \%$ had Vulnerability Index $1-2$ and the other half had Vulnerability \\
Index 7-8. & & & \\
\hline
\end{tabular}



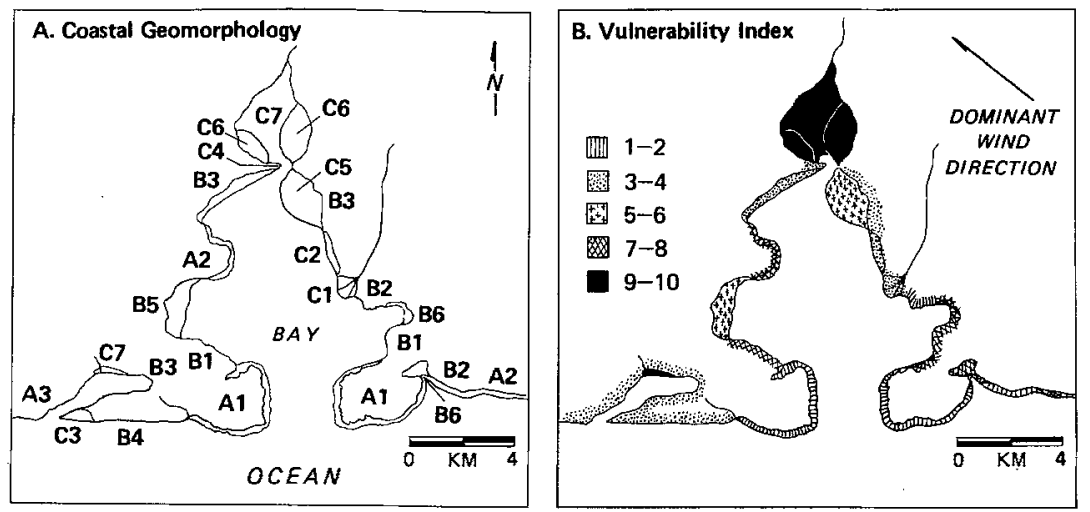

Fig. 3. (A) Coastal geomorphology of the hypothetical shoreline described in Table 3. (B) Application of the Vulnerability Index to shoreline types shown in 3-A

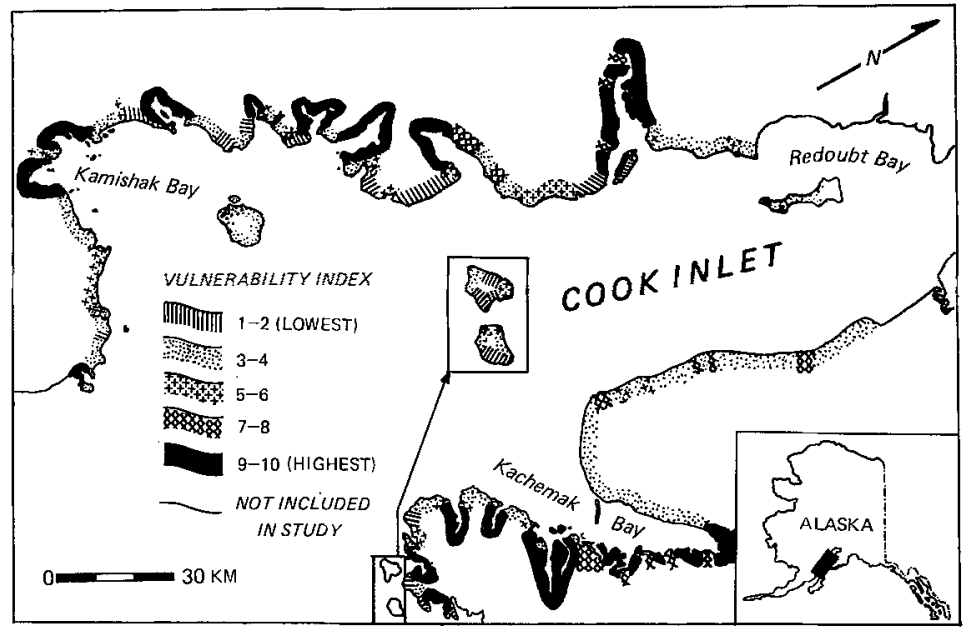

Fig. 4. Application of the Vulnerability Index to lower Cook Inlet section of the Alaskan coast (after Michel et al., 1978)

Laguna Madre and other bays and estuaries was held to a minimum (less than three metric tons of visible tarballs and mousse), according to preliminary estimates. The majority of oil impact was confined to the mixed sand and shell beaches of the south Texas coast. According to preliminary observations, there have been no widespread incidences of toxicity in either the Ocypode (ghost crab) backshore community, the Callianassa (ghost shrimp)-Donax (surf clam)-Haustoriid (amphipod) nearshore community, or the intervening foreshore ecotone.

The need to include offshore Vulnerability Index sampling during contingency planning is evidenced by the finding of weathered oil, both in the water column and in offshore bottom sediments during the "Ixtoc I" spill as well as after the "Amoco Cadiz" (Gundlach \& Hayes, 1978). In some instances, much pre-spill offshore baseline chemistry and biological data may have been collected already during the outer continental shelf 
surveys. Where available, these data generally provide the necessary baseline information, preventing expensive unnecessary duplication of sampling efforts offshore. Where these data are unavailable, offshore baseline sampling surveys should be included.

The Vulnerability Index is, thus, a tool which provides coastal managers or oil-spill contingency planners with the maximum amount of information on the potential impact on coastal environments. In essence, the Vulnerability Index assists in formulating the first line of defense against oil or hazardous substance spills in the environment.

\section{CONCLUSIONS}

The task of scientific assessment of the complex environmental consequences of large spills of oil and other hazardous substances has stimulated development of improved strategies for rapid and valid collection of ecological data. The method proposed here is termed the "integrated zonal method of ecological impact assessment", which combines a rapid geomorphic/geologic mapping technique with a quantitative ecological and chemical sampling strategy. This provides a rapid assessment technique which is useful in establishing chemical and biological baseline data; it also allows a method for quantifying the extent of ecological impact during first-order assessment studies conducted at the time of initial spill impact. Second- and third-order assessment studies, which emphasize chronic effects, may also employ a modified version of this integrated zonal technique to determine post-spill impact.

The "Peck Slip" oil spill in northeastern Puerto Rico provides an excellent example of the practicality, usefulness, and adaptability of the integrated zonal method in both first- and second-order assessment studies. Ecological damages measured during first-, second-, and third-order response studies may be translated into economic damage through the damage assessment process.

The need for pre-spill contingency planning, which establishes a pre-spill chemical and biological baseline, is urgent - especially in areas where oil-spill impact seems likely to occur. The use of the Vulnerability Index (a method of determining susceptibility of different coastal environments to oil-spill impact based on geomorphic and ecological sensitivity) in pre-spill planning is demonstrated in several different study areas. This Vulnerability Index assists oil-spill planners and decision-makers in formulating a first line of defense against impact by oil and hazardous substance spills.

\section{LITERATURE CITED}

Butler, J. N., 1978. The largest oil spills: inconsistencies, information gaps. - Ocean Ind. 13, 101-110.

Chan, E. I., 1977. Oil pollution and tropical littoral communities: biological effects of the 1975 Florida Keys oil spill. - Proc. Oil Spill Conf. 1977, 539-542.

Gundlach, E. R. \& Hayes, M. O., 1978. Vulnerability of coastal environments to oil spill impacts. Mar. Technol. Soc. J, 12, 18-27.

Hayes, M. O. \& Gundlach, E. R., 1978. Coastal processes field manual for oil spill assessment. Research Planning Institute, Columbia, S. C., 175 pp.

Hess, W. N. (Ed.), 1978. The Amoco Cadiz oil spill. - NOAA/EPA Spec. Rep., 283 pp.

Michel, J., Hayes, M. O. \& Brown, P. J., 1978. Application of an oil spill vulnerability index to the shoreline of lower Cook Inlet, Alaska. - Environ. Geol. 2, 107-117.

Robinson, J. H., 1979. Peck Slip oil spill: preliminary damage assessment. NOAA/OCSEAP, Boulder, Colo., 249 pp. 